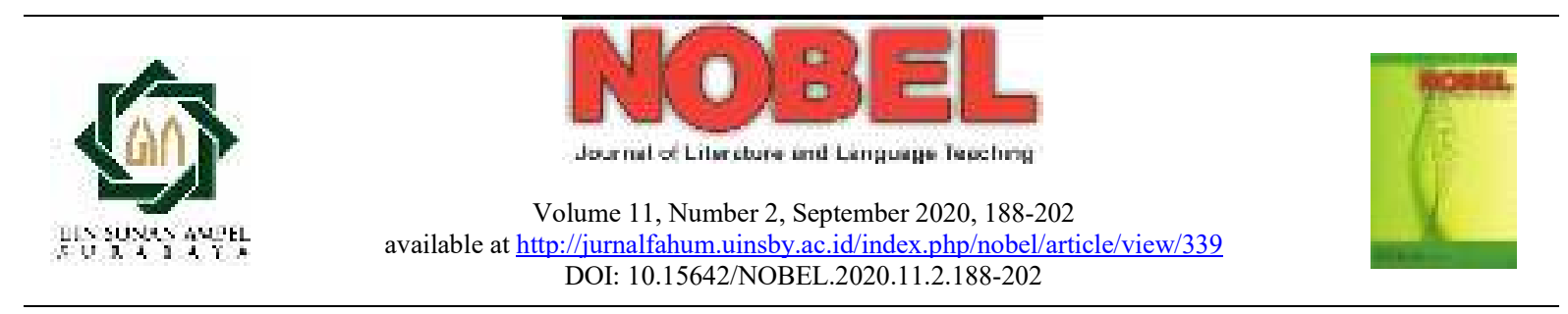

\title{
THE EFFECTIVENESS OF MOBILE ASSISTED LANGUAGE LEARNING (MALL) ON ESL LISTENING SKILL
}

\author{
Mehedi Hasan $^{1}$, A. B. M. Shafiqul Islam ${ }^{2}$ \\ ${ }^{1}$ York University, Canada \\ ${ }^{2}$ King Khalid University, Kingdom of Saudi Arabia
}

\begin{tabular}{l}
\hline Article Info \\
\hline Article History: \\
Received June 2020 \\
Accepted August 2020 \\
Published September 2020 \\
\hline Keywords: \\
Mobile Assisted Language \\
Learning (MALL), \\
ESL/EFL Listening Skills, \\
Appropriate Strategies \\
\hline
\end{tabular}

Abstract
Using mobile technology in English learning and teaching has been on
the rise all over the world over the past few decades and hence, has
received considerable attention and importance from academics in
recent years. As a result, several experimental studies have been carried out about the use and effectiveness of mobile phones in the teaching/learning process. However, there have been only a few studies on mobile-assisted listening comprehension. This study aims to explore whether Mobile Assisted Language Learning (MALL) is effective in teaching/learning listening skills to the students of university-level English language programs and could better enhance students' listening ability. It also endeavors to assess why some MALL strategies/techniques are more effective than others. This study uses a qualitative research method. It exclusively uses the relevant secondary materials available on the broader topic- the use and efficacy of mobile phones in teaching/learning listening skills. The results indicated that the MALL is meaningfully efficacious in teaching/learning ESL/EFL listening skills. Therefore, using appropriate strategies could positively contribute to bringing about better learning. Besides outlining a brief overview of MALL, the study also recommends some practical and useful stratagems that ESL/EFL educators can use while designing MALL listening tasks/activities. 


\section{INTRODUCTION}

Using technology in the teaching and learning of English as a foreign language (EFL) has received much importance and attention over the last few decades throughout the world. As a result, teaching and learning have incorporated technological skills in it and thereby become more technology-dependent. This integration of many sophisticated devices in education has initiated many technology-based approaches and methods which have broadly helped learning come out of the constraints of time and place, thus enabling learners to study whenever and wherever possible. These trends have also introduced a new learning/teaching practice- transforming from outmoded classroom learning to electronic learning (E-learning). One such trend is Mobile Assisted Language Learning (MALL), which has appeared as a field of study since the 2000s.

Because of incredible improvements in mobile communication systems and wireless technologies, mobile phones have proved to be the most useful communication mode that can also act as a language learning and teaching tool. With such a learning tool, a student can enjoy a rare opportunity of being a teacher, and a learner simultaneously and thereby can control the learning procedure and growth in his/her arena based on his/her cognitive capability. MALL thus draws on improved mobility, smooth accessibility, and flexibility provided by mobile technologies. At the same time, the features of mobile technologies such as texting, voice and video recording, access to the internet, and cameras eventually empower learners with abilities with which they can increase their communicative abilities and get access to reliable resources. Teaching or learning through mobile phones also uses the context, which not only positively influences the learning style but also acts as a catalyst in the overall learning/teaching process. Therefore, MALL has opened up the possibility to download and use free electronic materials, specific applications, and programs of the English Language that may aid students in developing language skills and knowledge on grammar and vocabulary. MALL, therefore, attempts to bring students and teachers out of the classroom contexts into the real world. Very recently, the use of MALL in the arena of English as a Second/Foreign Language (ESL/EFL) has increased ever than before. Smart technologies such as 5G networks, WIFI, touch screens, photo and video options, code reading capabilities, voice and image recognition, MP3/4 players, screen sharing facilities, GPS, SMS, MMS, e-mail, virtual gaming, internet, and most lately, mobile-based applications and Web 2.0 resources have helped mobile devices overcome the limitations they had in the late 1990s and early 2000s. 
Moreover, portability, connectivity, and affordability have made such devices more popular and given more advantages over PCs or laptops. Regarding connectivity, the mobile system contains an inherent capability of being connected and communicated with the learning website, which can use the wireless network of the device in order to get access to the learning resources, including Short Message Service (SMS) and mobile e-mail. Portability allows pupils to carry mobile devices with them since it provides learning that is theoretically independent of setting, time, and space, thus incorporating students' likings and timetables (Abu Sa'aleek, 2014). It is a teaching process that uses mobile phone technology to underscore learner centeredness and independence. As a result, more and more teachers are using mobile devices in teaching English inside and outside the classroom in face-to-face, blended, and online language learning programs. Recent studies show how mobile devices are being used in teaching vocabulary (Zhang, Song and Burton, 2011), grammar and reading (Wang and Smith, 2013), grammar and writing (Li and Hegelheimer, 2013), listening and speaking (Rueckert, Kiser and Cho, 2012) and how learners can actively engage in learning activities which provide them to learn more from their community of practice. Some researchers also focus on teachers'/students' beliefs (Kim, Ruekert, Kim and Seo, 2013) and classroom pedagogy (Burston, 2014). However, a few studies measure the effectiveness of MALL in teaching/learning English in ESL/EFL classrooms. Thus, this study aims to explore the efficacy of MALL in teaching/learning listening skills to the students of university-level English language programs and assess why some MALL strategies/techniques are more effective than the others. This paper is divided into six sections. The first section gives a brief overview of the MALL and its emergence features and application in the classroom. The second section briefly outlines the research questions, criteria, and methodology in selecting the relevant literature. The third section details the theoretical framework of using MALL in teaching and learning listening skills. The fourth section reviews the current researches and any relevant literature on MALL in teaching listening. The fifth section summarizes and discusses the critical points of the literature. The last section recommends strategies that ESL/EFL teachers can use in designing MALL listening tasks/activities.

\section{Definition of MALL}

MALL is an approach to the process of language learning supported and enriched through handheld mobile tools. This mode of learning occurs when the student frequently changes his place of learning and is not in a static setting. MALL is a descendant of CALL or Computer-Assisted Language Learning and a subclass of Mobile Learning (M-Learning) and 
Computer-Assisted Language Learning. M-Learning academics agree that it should not be limited to merely learning with mobile technologies; rather, it can be seen as learning across physical and virtual settings that are assisted and supported by convenient devices (both handheld and wearable) as well as communication and social network devices. At the cores of the mobile-language learning is the mobility of the learner across contexts, easy access to people, resources (readily available both on the device and on the internet), and other technological gadgets (like in-built device capabilities and internet-based learning apps), along with mobile phone-mediated assistance and supports.

\section{Emergence of MALL}

With the emergence of different methods and approaches, the use of technology in varied forms in the classroom also emerged. For example, the Audio Lingual method and its implementation in teaching and learning primarily emphasize setting up language laboratories, which slowly but increasingly turned out to be the practice of that period (Salaberry, 2007). Influenced by the theory of behaviorism, drill-based computer-mediated training frequently held in those language labs in the 1960s, was eventually succeeded by a more urbane method named Computer Assisted Language Learning (CALL) in the 1990s.

However, the foundation of MALL dates back to the year of 1972 when Alan Kay delineated a model in teaching and learning in which he talked about using a portable personal computer called the 'Dynabook.' Although that model did not prove successful, it is still widely viewed by many to be the first idea for the laptop computer available nowadays. Long after that, a project titled 'Apple Classrooms of Tomorrow' was undertaken in 1991 to study the impact of technology on student achievement. It was the first such attempt that involves teachers working in high-tech classrooms. Later, PDA (Personal Digital Assistant), a pocket computer or a palmtop, was introduced in the classroom, which paved the way for MALL. PDAs got immense popularity during the last decade of the $20^{\text {th }}$ century, and those devices were the predecessors to what we call smartphones today. Though PDAs were furnished mainly and used for business purposes, and not intended for teaching needs, their utilities in book storage, entering notes, functioning as cellular phones, and sending faxes were viewed as the early breakthroughs in the digitization of education. Besides PDA, other technological tools that contribute to language teaching and learning are multimedia mobile phones, MP3 and DVD players, and electronic dictionaries (Zhao, 2005, p. 447). Later we notice the emergence of Amazon Kindle, iPhone, and iPad. Now, a single device - a mere smartphone can accomplish all these activities at a time which could previously be completed 
sporadically by multiple devices.

\section{Features of MALL}

Like other approaches and methods, students and teachers are the keys and active stakeholders and participants in the MALL. Being an active participant means that students should be accountable for their learning and that teachers merely act as the facilitators. There is a wide range of learning tools available for the students, and the overwhelming amount of information can overstuff them. In that case, teachers have to show learners the appropriate strategies to select the most usable content and guide them by recommending the most effective learning tools and methods. Simultaneously, students need to exhibit enough prudence, maturity, and accountability regarding the use of technology since students do not directly learn from technologies; instead, these electronic tools help mediate the thinking and learning process. In this regard, learners need to display an advanced degree of selfmonitoring, which does provide choices to students, and at the same time, engage them in goal fixing, self-regulation, self-evaluation, synchronization of psychological activities, and self-efficiency. Thus, in a mobile-incorporated learning milieu, learners must exhibit more self-sufficiency, autonomy, and individuality. Through these tools, learners can produce and share multi-dimensional texts, interconnect voluntarily with people anywhere across the globe, understand the use of language outside the formal classroom environment, investigate the learning needs and production and eventually create things to offer proof of improvement. Even if all the students do not have mobile phones, they still can work in pairs and small clusters to make the happenings efficacious. Moreover, MALL is one of the best alternatives in this regard through which learners can be in constant contact with their fellow friends, peers, or instructors, anytime, anywhere. (Turc, 2017).

\section{Applications of MALL in the Classroom}

MALL manifests itself in various forms, including learning apps on education, electronic books and libraries, course administration systems, audio, video and images, QR codes, and social media. Nowadays, different types of apps, particularly in the education sector, are flourishing in terms of quality and quantity and most of which are reasonably priced or free in some cases. While learning English with the help of technology, it must be kept in mind that many of these apps are originated from untrustworthy sources and hence, deliver low quality. When we develop activities for students, we need to consider the availability of the salient functions of mobile phones like having a camera (video and photos), voice recorder, 
calendar, QR codes, mp3/video player, maps, notes, and eBook reader. It should, of course, be ensured that the facility of browsing the internet must be available (Lightfoot, 2015, mentioned in Turc, 2017).

The implementation of MALL can be multi-modal, including face-to-face, distant, or online. However, many researchers underscored students' presence as a paramount aspect in executing MALL in the classroom. Colpaert (2004) has also stressed the need to ensure a proper learning atmosphere before bringing mobile machinery into use. Similarly, Salaberry (2001) has reasoned against "technology-driven pedagogy," highlighting the point that despite their substantial advantages, nothing so far has demonstrated that any form of technological devices can fundamentally perform better than the old-fashioned methods of instruction. Finally, as Beatty (2003) has asserted, "Teachers need to be concerned about investigating time and money in unproven technology" (p.72). Above all, using any high-tech devices in education should bring forth an effective technique/method since these tools are not teachers instead of teaching devices.

\section{Research Questions}

This study focuses on two research questions:

1. To what extent is MALL effective in teaching listening skills to ESL learners?

2. Why are some MALL listening strategies more effective than others?

One hypothesis regarding the first research question was formed. Based on the readings and teaching experiences, it is assumed that the mobile-based teaching of listening comprehension skills is effective. Since the second question is exploratory in nature, no prediction could be made.

\section{REVIEW OF LITERATURE}

\section{ESL Listening Skill}

Over the years, ESL listening practices have developed over the beliefs and assumptions teachers have about listening skills. Brown and Lee (2015) speculate that ESL teachers have the commonly held misconceptions that listening is a passive, one-way, and individual process. They also reveal that teachers believe that listening is acquired unconsciously, equals reading comprehension, and listening and speaking should be taught separately. To argue that listening is active, multidirectional, and a conscious cognitive process, Brown and Lee (2015) thus describe the strategies involved in listening comprehension processes. Referring Clark and Clark (1977) and Richards (1983), Brown and Lee (2015) mention that 
listening comprehension includes listening auditory sounds, determining the function of the speech event, activating scheme, assigning literal meaning, assigning intended meaning, determining the demand of short/long term memory and retaining essential information and meaning (p. 319). Brown and Lee (2015) also support Richard's (1983) comprehension taxology as micro skill (skills at the sentence level) and macro skill (skills at discourse level) and state that the former is synonymous to the bottom-up approach and the latter to top-down approach (p. 326). They also mention several tasks and activities a teacher can use to teach listening comprehension skills. They mention the techniques/tasks as reactive (listening to surface structure), intensive (focus on language components), responsive (designed to elicit a response), selective (scan for specific information), extensive (aims global understanding of conversation), and interactive (learners actively discuss, debate, converse, role-play in pairs/groups) (pp. 328-330). This paper, in the discussion section, explains how the above tasks/techniques apply in teaching mobile-based listening.

\section{MALL in teaching/learning listening}

In the history of MALL listening research, the focus has always been on the teacher-student interaction, the teaching/learning strategies, the learning tasks, and their effect on teaching/learning. Vandergrift (2011) claims that higher-level learners successfully apply the listening strategies in MALL listening. According to him, lower level learners use a bottomup approach and have difficulties while listening in real-time on their devices. Therefore, he suggests training students with strategies and designing the activities accordingly. Gilakjani and Ahmadi (2011) argue that prior learning activities help students process information in mobile-assisted listening activities. They insist that prior learning also helps students extend listening and stimulate interpretation and reflection. Kim (2013) demonstrates that in MALL, group listening activity helps improve listening more than individual activity. Read and Barcena (2016) cite several current research on MALL-based listening and show that podcast is the most common type of listening activity given to ESL/EFL listening. They also mention that MALL-based teaching/learning is effective mostly when the tasks become part of the summative assessment; otherwise, students sometimes tend not to use those tasks (p. 295).

\section{Literature Review}

In the last decade, there has been a substantial upsurge in researching the effectiveness of MALL in the ESL/EFL listening classroom. The following review of the literature shows the need for studies in mobile-based listening in ESL/EFL classrooms. It then discusses the variety of teaching tools, strategies, techniques, activities, and resources teachers and 
educators use in different educational settings. Read and Kukulska-Hulme (2015) mention the importance of listening comprehension for ESL/EFL learners in mobile app-based learning. Their study reveals how the use of mobile apps can motivate students and facilitate listening activities. The research also shows that MALL based activity ultimately led students to practice listening using authentic materials such as news broadcast on radio or television. They also observe that creating various listening content based on students' interest and incorporating social media such as Facebook increase learner motivation (p. 1334). Artyushina and A. Sheypak (2018) express the need for using cellphones to teach listening comprehension to young learners in Russian Technical University. According to them, cellphones, which are immensely popular among young learners for entertainment purposes, can also be an effective tool to improve ESL/EFL listening comprehension skills. Their research demonstrates that using learner's motivation towards any gadgets and efficient use of content in MALL based learning can inspire them not only to learn outside their classroom but also to encourage them to create their podcast based scientific research (p. 6). Hsu et al. (2013) express the necessity of using various modes of display of video captions in MALL based language learning. Through experimenting with young learners, the authors conclude that better vocabulary acquisition occurs only when target-word strategies are effectively used in listening comprehension for low-achievement students. The above studies thus suggest that research on the MALL based listening is essential as they help ESL/EFL practitioners determine the specific strategies (individual or group), devices (cell phones, iPod, MP3 player), modes (audios only, or videos with the caption), activities ( listening, responding and sharing), platforms (apps, websites), and understand the affordances (availability, accessibility) and limitations (dislike towards specific tasks) of each of the factors in their own ESL/EFL classroom context. In recent years, educators and researchers have experimented with the aspects mentioned above to assess the effectiveness, benefits, and challenges of using MALL in teaching/learning listening comprehension skills.

In this study, the researchers attempt to focus on four recently conducted empirical studies about using mobile-based listening activities as an individual task, which observes some development in EFL/ESL listening in the control group over the experimental group. The studies also found that MALL contributes as a critical variable to effective listening strategies. In Korea, Kim (2013) investigates the adult learners' development of listening abilities after using specific mobile applications in a college EFL language course. She divided 41 students into an experimental group and a controlled group enrolled in the TOEIC program. The students received almost the same TOEIC score and materials before the 
beginning of the program. In addition to class activity, the experimental group was assigned listening tasks two times a week as opposed to the controlled group's class activity only throughout the entire semester. The experimental group used English apps and broadcast programs such as TBS, e-FM, and EBS on Air for ten weeks and then retook the TOEIC test. The TOEIC listening comprehension test result shows that the experimental group test score outperformed the controlled group test score $(\mathrm{M}=422.19, \mathrm{SD}=114.69$ in the control group; $\mathrm{M}=490.00, \mathrm{SD}=87.09$ in the experimental group, $\mathrm{p}<.05$ ). Based on the result, the researcher claims that smartphone apps "as a learning tool can be a variable" (p. 22) and can significantly contribute to the teaching/learning of EFL listening skills. The researcher also conducts an open-ended question survey with the experimental group to study the attitude towards using mobile apps. Most participants mentioned that access to mobile devices anywhere and anytime was the greatest affordance of mobile phone learning. They also mention that apps gave them authentic listening practice materials easily, and they had "fun" using the app (p. 23).

Azar and Nasiri (2014) investigate the effectiveness of MALL on English listening comprehension skills on Iranian university students. They experimented with 70 students considered homogenous formed on their pretest (Oxford Placement Test). Grouped into four sections- two experimental and two comparison groups, the students received 14 lessons on developing skills and sub-skills for listening comprehension. While the experimental groups were given mobile-based audiobooks, the comparison groups were given regular audio materials such as CD-ROM/cassette audiobooks for lessons and practice. After 16 weeks of treatment, a post-test was conducted between the two groups to measure the listening comprehension skills gained through the treatment. The post-test result shows that the experimental groups outperformed the comparison groups $\{\mathrm{t}(69)=2.38, \mathrm{p}<0.05\}$. From the test results, the researchers claim that the mobile-based listening audiobook instruction was effective.

To investigate learners' experience in using mobile-based audiobooks, the researchers conducted a questionnaire and interview with the participants. They found that MALL materials were easily accessible to the participants, and for being portable, participants could use mobile devices "anywhere, anytime" (p. 1841). The researchers also mention that, through MALL listening lessons, participants had "more opportunity to negotiate meaning with their teachers and their peers" (p. 1841). The research mentions that teachers explained any questions students had regarding the tasks, but it does not mention clearly how the participants negotiated meaning with peers. The study suggests that mobile-based listening 
comprehension teaching was effective and positively impacted teaching/learning listening skills.

Zhang (2016) explores mobile technology in teaching/learning listening in the EFL classroom and student motivation in using mobile-based activity at a university in China. Dividing 120 homogenous language ability students equally into the experimental and control group, the researcher gave each group a 2-hour listening instruction for ten weeks. On the one hand, the experimental group received all instruction through mobile phones and used Keke English and Easy IELTS to practice at home. On the other hand, the control group received traditional CD-based in-class instruction only. Both groups appeared in a post-test and were given a questionnaire towards the end of the program. The post-test result demonstrates that the experimental group "significantly outperformed" the control group on the post-test $(\mathrm{p}=.021<0.05)$. The researcher claims that implementing MALL resulted in increased listening comprehension. In the questionnaires, $88 \%$ of the students mention that their "filler time" could be used with MALL activities. The students also mention that they could carry their devices and learn at any time, in any place at their convenience, and could segment their study period, which let them control their learning process (p. 3).

In Japan, Yamada et al. (2011) study the effectiveness of mobile-based listening teaching/learning materials for business people. The researchers examined 39 (20 sales and 19 non-sales) employees enrolled in a Business English program at the company's training center. All participants had to take a preliminary test to understand their language level and then were given English for Specific Business Purposes (ESBP) listening materials to be used for over three weeks. After three weeks, the participants had to respond to a post-project questionnaire and take a post-test (Global Test of English Communication, GTEC) and a customized Materials-specific listening test. The post-test result demonstrates that in both the post-tests, the sales and non-sales employees scored higher than the pretest (sales personnel $\mathrm{z}$ $=-2.44, \mathrm{p}<.05$; non-sales personnel $\mathrm{z}=2.71, \mathrm{p}<.01$ ), and there was no substantial variation between the scores of two groups $(\mathrm{z}=0.51)$. The authors claim that mobile-based disciplinespecific listening materials were equally effective for both group learners. They also conducted a second survey after two months of the program to see how much they could use the materials in real-life situations. They found that the salespersons were better able to use the content of the program as their needs to correspond in English were higher than the nonsale group (pp. 57-60). This suggests that the ultimate effect of any successful mobile-based listening program depends on learners' needs. In other words, if the learners' needs (work situation in this case) do not align with the content (EBSP materials in this case), the learners 
may learn it, but not be able to use it in real-life situations.

Recent studies also endeavor to compare mobile-based listening activities as an individual task to a group task and found that the mobile task done in groups is more beneficial for students than the individual task. Read and Kukulska-Hulme (2015) study the benefits of using mobile apps for listening comprehension training to promote motivation and students' self-learning in a mandatory university entry program in the UK. They experimented with students of 90 heterogeneous language levels (from A1 to $\mathrm{C} 1$ ) by putting them into two equal groups (Individual Learning Group and Facebook based Social Learning Group). They were given the app Audio News Trainer (ATN) to practice listening podcasts for ten weeks. Each group participants received instructions on how to participate. The researchers used app data (comments and content) and pre and post-questionnaire to examine students' learning activities and motivation. The researchers found that in the Individual Learning Group, only nine students listened to the podcasts for 10 minutes a day, and only three continued listening throughout the weeks. Only two students mention that they will continue the apps after the course is over.

By contrast, in the Social Learning Group, 33 students used the app for 30 minutes a day consistently, and some students were even proactive and wanted to use the app even after the course was over. Participants in this group summarized their feelings on the podcasts, congratulated others, and commented on others' summaries "as if they were part of a teaching team" (p. 333). Based on the result, Read and Kukulska-Hulme (2015) claim that a) the news-based app is an "effective domain" for practicing listening comprehension, b) social media-based listening, which facilitates interaction, increases student motivation, and c) mobile-based apps can provide learners with a continuous practice context.

Read and Barcena (2016) extend their focus on the study of Read and Kukulska-Hulme (2015) and study the effect of peer interaction to motivate, support, and scaffold student learning in the listening comprehension. The authors found that the experimental group not only spent more time than the Individual group but also found the task enjoyable. They found that $18 \%$ of students in the group whom they called e-leading students were connected regularly, kept on tasks, participated in interactions, answered peers' questions, searched for supporting evidence, corrected others' mistakes, encouraged demotivated students, and served as an intermediate with the teachers. (p. 305). Such students contributed to the overall participation of the students in the Social Group. The result also shows that since there was no direct teacher feedback on students' tasks, students became self-motivated to play their 
role in the Facebook-based ATN app interaction. The result indicates that students' proactive behavior in an interactive group activity promotes learning.

\section{METHOD}

This is a review article that uses a qualitative research method. Review articles are immensely important since the reviewers, while reviewing the already available materials, endeavor to suggest new research directions, strengthen support for existing theories and identify patterns among current research studies. For researchers, review articles provide an excellent overview of the existing literature on a topic. As a review article, this study is based on the secondary references/works, including relevant articles and books which tend to reanalyze, interpret, or review the past available data on a subject matter. However, this research has not included all the materials available on the subject of the present research; instead, it attempts to find such literature that fits the topic and, therefore, follows a particular set of inclusion and exclusion criteria while selecting the research materials for review. Following are the criteria:

a) All articles reviewed in this paper were electronically searched on the York University library database, Google scholar, or peer-reviewed online journals.

b) All articles chosen for the current research are empirical studies in nature.

c) All articles were searched with a specific focus on "MALL in teaching ESL/EFL listening skills.

d) Any articles that focused on other educational settings (e.g., elementary, high school) or other languages (Second languages other than English) were excluded from the study.

e) Any articles before 2010 were excluded as smartphone-based MALL learning/teaching started since 2007.

\section{RESULTS AND DISCUSSIONS}

\section{Research question: 1}

The above literature suggests that mobile-based listening comprehension teaching/learning is effective to a certain extent in different educational settings. The quantitative data indicate that some strategies/tools ( $p<.05$ in Azar and Nasiri, 2014; Kim, 2013; Zang, 2016) were more successful than the other ( $p<.01$ in Yamda et al., 2011for nonsales). Read and Barcena (2015) do not quantify the success between the Individual Group and the Social Group. However, higher student participation (88\%) in the Social learning group than the Individual group (18\%) shows that one strategy was more motivating and 
engaging than the other. Therefore, in response to the first research question, it can be claimed that mobile-based teaching/learning listening is effective in some ways in ESL/EFL teaching. Their study also demonstrates that portability, accessibility, affordance, freedom of use, and enjoyment are the most common affordances of successful MALL based listening.

\section{Research question: 2}

Read and Kukulsha's (2015) and Read and Barcena's (2016) findings clearly indicate that some mobile-based ESL listening strategies are more successful than the other. In their studies, the Social Group was more successful as they were more engaged and motivated than the Individual Group. In the former group, students were proactive and interactive. Besides listening to the audios, they liked others' comments, summarized the audio, commented on others' comments, asked and answered questions, corrected others' mistakes, stimulated less motivated students, and took the role of mediators. Although the ATN app tasks were optional and did not add credit to their final grades, students became proactive as they could interact with peers.

Nonetheless, as students could not interact in Individual Group, they were less motivated and chose not to participate. Their research suggests that to make a MALL tool successful, the teachers/designers should make it interactive. Azar and Nasisr (2014) also recommend that students learned well when they could interact and negotiate meaning with the teachers and peers. The above findings support Brown and Lee's (2015) idea that listening performance can be helpful if learners participate actively in "discussions, debates, conversations, role plays, and other pair and group work" (p. 330).

Most of the above studies also suggest that using authentic materials (Kim, 2013; Yamada et al., 2011), understanding learners' needs (Yamada et al., 2011), breaking tasks into segments (Zhang, 2016), and providing supplementary tasks (Read and Barcena, 2015) are some of the fundamental design principles of successful mobile-based listening tasks. Furthermore, interactive tasks provide learners with opportunities to bring their other skills, such as writing, interpersonal skill, and intercultural communication skills into practice.

\section{Recommendations}

Based on the above discussion and some current research studies, we would recommend some strategies that ESL/EFL teachers can use while using mobile devices in teaching listening. Firstly, a teacher should design the tasks based on the needs of the students. Yamada et al. (2011) demonstrate how the same material design may result in more success, depending on the needs of the learners. The sales group was more successful as they could 
use their learning in a real-life situation. Their findings support the idea that the more the materials address the needs of the learners, the more chances are that the mobile-based tasks would be successful. Secondly, teachers should use not only an authentic task but also authentic materials. The studies of Kim (2013) and Yamada et al. (2011) demonstrate that authentic materials and tasks motivate learners to connect activities to their real-life situations. Thirdly, teachers should use short and scaffolded tasks to create a stress-free learning environment for learners. Azar and Nasiri (2014) reveal that students enjoy working on portable devices anytime and anywhere. Zang (2016) also demonstrates that students like carrying their devices, work in places of their convenience, and segment their study period. His findings suggest that teachers should keep learning activities and tasks "short and succinct" (Stockwell and Hubbard, 2013, p. 9). Fourthly, teachers should acknowledge and plan for accommodating all level learners (Stockwell and Hubbard, 2013, p. 9). Both Azar and Nasiri (2014) and Read and Barcena (2015) express that learners like to participate in various ways. Such participation option motivates learners as they can choose from multiple possibilities. Fifthly, teachers should think of the affordances and limitations of the activities, tasks, and apps before they design (Stockwell and Hubbard, 2013, p. 9). Read and Barcena (2016) suggest how the same task can be more effective if appropriately designed. An interaction-based app seems more enjoyable and effective for learners than apps used for selfstudy. Therefore, mobile-based listening tasks should be made interactive where possible. Sixthly, teachers should provide guidance and training to learners about the apps before introducing them to the course. In most of the above studies, learners were trained to use the app or tool on their devices successfully. Finally, teachers should make some portions of the task part of a summative assessment. Read and Barcena (2016) assert that in the individual group, learners were found less motivated since the task was not graded and not a part of the final assessment. Therefore, it is recommended that teachers should impart some portions of the tasks in the final assessment.

\section{CONCLUSION}

In general, this review suggests that MALL is significantly effective in teaching/learning ESL/EFL listening skills, and using proper strategies may result in better learning. Since MALL is relatively new in ESL/EFL teaching and learning arena, it is recommended that further research is required to see which level learners (beginner, intermediate or advanced) are more benefited from MALL and its use. It is also recommended that teachers should use multiple MALL strategies for better and effective ESL/EFL listening. 


\section{REFERENCES}

Abu Sa'aleek, A. O. (2014). A Review of Emerging Technologies: Mobile Assisted Language Learning (MALL). Asian Journal of Education and E-Learning, 2(06), 469475.

Retrieved from https://pdfs.semanticscholar.org/bf41/8cc63284e778f4a71892b086fe1e655f8415.pdf

Artyushina, G., \& Sheypak, O. (2018). Mobile Phones Help Develop Listening Skills. Informatics, 5(32), 1-7. DOI:10.3390/informatics5030032

Azar, A. S., \& Nasiri, H. (2014). Learners' attitudes toward the effectiveness of mobileassisted language learning (MALL) in L2 listening comprehension. Procedia-Social and Behavioral Sciences, 98, 1836-1843. DOI: 10.1016/j.sbspro.2014.03.613.

Beatty, K. (2003). Teaching and researching computer-assisted language learning. Essex: Pearson Education.

Brown, H. D., \& Lee, H. (2015). Teaching by principles: An interactive approach to language pedagogy. White Plains, NY: Pearson Education.

Burston, J. (2014). MALL: The pedagogical challenges. Computer Assisted Language Learning, 27(4), 344-357. DOI: 10.1080/09588221.2014.914539

Colpaert, J. (2004). From courseware to coursewear?. Computer Assisted Language learning, 17(3-4), 261-266. DOI: 10.1080/0958822042000319575

Gilakjani, A. P., \& Ahmadi, M. R. (2011). A study of factors affecting EFL English listening comprehension and the strategies for improvement. Journal of Language Teaching and research, 2(5), 977. DOI: $10.4304 / \mathrm{j} 1 \mathrm{tr} .2 .5 .977-988$

Hsu, C.-K., Hwang, G.-J., Chang, Y.-T., \& Chang, C.-K. (2013). Effects of Video Caption Modes on English Listening Comprehension and Vocabulary Acquisition Using Handheld Devices. Educational Technology \& Society, 16 (1), 403-414. Retrieved from https://www.ds.unipi.gr/et\&s/journals/16_1/35.pdf

Kim, D., Rueckert, D., Kim, D. J., \& Seo, D. (2013). Students' perceptions and experiences of mobile learning. Language Learning \& Technology, 17(3), 52-73. Retrieved from http://lit.msu.edu/issues/october2013/kimetal.pdf

Kim, H. S. (2013). Emerging mobile apps to improve English listening skills. Multimedia Assisted Language Learning, 16(2), 11-30. DOI: 10.15702/mall.2013.16.2.11

Lightfoot, A. (2015). A beginner's guide to mobile learning in English language teaching Video recording, Youtube. Viewed on 01 May 2020, https://www.youtube.com/watch?v=yvNZ8_iyiYc>

Li, Z., \& Hegelheimer, V. (2013). Mobile-assisted grammar exercises: Effects on selfediting in L2 writing. Language Learning \& Technology, 17(3), 135-156. http://dx.doi.org/10125/44343

Read, T., \& Bárcena, E. (2016). The development of oral comprehension via mobile-based social media and the role of e-leading students. In A. Palalas \& M. Ally (Eds.), The international handbook of mobile-assisted language learning. Beijing: China University Press.

Read, T., \& Kukulska-Hulme, A. (2015). The role of a mobile app for listening comprehension training in distance learning to sustain student motivation. Journal of 
Universal Computer Science, 21(10), 1327-1338. DOI: 10.3217/jucs-021-10-1327

Rueckert, D., Kiser, R., \& Cho, M. (2012, March). Oral language assessment made easy via Voice Thread! In TESOL International Convention and English Language Expo, Philadelphia, PA, March (pp. 28-31).

Salaberry, M. R. (2007). The use of technology for second language learning and teaching: A retrospective. The modern language journal,85(1), 39-56. DOI: $10.1111 / 0026$ $\underline{7902.00096}$

Smith, S., \& Wang, S. (2013). Reading and grammar learning through mobile phones. Language Learning \& Technology, 17(3), 117-134. Retrieved from http://1t.msu.edu/issues/october2013/wangsmith.pdf

Stockwell, G., \& Hubbard, P. (2013). Some emerging principles for mobile-assisted language learning. The International Research Foundation for English Language Education, 1-15. Retrieved from http://www.tirfonline.org/english-in-the-workforce/mobile-assistedlanguage-learning

Turc, L. (2017). Mobile-Assisted Language Learning (MALL). RATE Issues Summer, 19. https://rate.org.ro/blog2.php/1/mobile-assisted-language-learning-mall

Vandergrift, L. (2011). Second language listening. Handbook of research in second language teaching and learning, 2, 455.

Yamada, M., Kitamura, S., Shimada, N., Utashiro, T., Shigeta, K., Yamaguchi, E., . . . Nakahara, J. (2011). Development and Evaluation of English Listening Study Materials for Business People Who Use Mobile Devices: A Case Study. CALICO Journal, 29(1), 44-66. Retrieved May 27, 2020, from www.jstor.org/stable/calicojournal.29.1.44

Zhang, H., Song, W., \& Burston, J. (2011). Reexamining the effectiveness of vocabulary learning via mobile phones. Turkish Online Journal of Educational TechnologyTOJET, 10(3), 203-214. Retrieved from https://www.researchgate.net/publication/259442040_Reexamining the effectiveness_o f_vocabulary learning_via mobile_phones

Zhang, Y. (2016). The Impact of Mobile Learning on ESL Listening Comprehension. $3^{\text {rd }}$ International Conference on Advanced Education and Management (ICAEM 2016). DOI: $10.12783 /$ dtssehs/icaem2016/4290

Zhao, Y. (2005). The future of research in technology and second language education. In Y. Zhao (Ed.), Research in technology and second language learning: Developments and directions (pp.445-457). Greenwich, CT: Information Age Publishing, Inc. 